\title{
Relative peripheral defocus and myopic progression in children
}

\author{
David A. Atchison
}

Received: 11 September 2013 / Accepted: 21 October 2013 /Published online: 12 November 2013

(C) Springer-Verlag Berlin Heidelberg 2013

Dear Editor,

Yamaguchi and colleagues [1] investigated peripheral optical quality and determined its relationship with axial elongation and myopic progression in children. On the basis that a "progressing group" of seven children had more initial hyperopic relative peripheral defocus than a "non-progressing" group of 22 children, despite both groups having similar initial central refractions and axial lengths, they concluded that progression of axial myopia in children is associated with hyperopic relative peripheral defocus.

I do not believe that the study supports this conclusion. While the central refraction difference between the two groups was not significantly different, this may be because of the small number in their progressing group; the initial mean refraction for the progressing group was about $1.4 \mathrm{D}$ more myopic than that of the non-progressing group, and this is expected to give more hyperopic relative peripheral defocus [2-4]. The similar axial length between the groups means little without information about the gender distribution, because males have about $0.5 \mathrm{~mm}$ longer axial lengths than females of similar refractions and age [5-7]; also, again, there may have been insufficient children in this group to show a real difference.

Conflicts of interest There are no conflicts of interest.

\section{References}

1. Yamaguchi T, Ohnuma K, Konomi K, Satake S, Shimazaki J, Negishi K (2013) Peripheral optical quality and myopia progression in children. Graefes Arch Clin Exp Ophthalmol 251:1663-1666, published online 13 June 2013

2. Atchison DA, Pritchard N, Schmid KL (2006) Peripheral refraction along the horizontal and vertical visual fields in myopia. Vision Res 46:1450-1458

3. Kang P, Gifford P, McNamara P, Wu J, Yeo S, Vong B, Swarbrick H (2010) Peripheral refraction in different ethnicities. Invest Ophthalmol Vis Sci 51:6059-6065

4. Chen X, Sankaridurg P, Donovan L, Lin Z, Martinez A, Holden B, Ge $J$ (2010) Characteristics of peripheral refractive errors of myopic and non-myopic Chinese eyes. Vision Res 50:31-35

5. Zadnik K, Manny RE, Yu JA, Mitchell GL, Cotter SA, Quiralte JC, Shipp MD, Friedman NE, Kleinstein RN, Walker TW, Jones LA, Moeschberger ML, Mutti DO, Collaborative Longitudinal Evaluation of Ethnicity and Refractive Error (CLEERE) Study Group (2003) Ocular component data in schoolchildren as a function of age and gender. Optom Vis Sci 80:226-236

6. Atchison DA, Jones CE, Schmid KL, Pritchard N, Pope JM, Strugnell WE, Riley RA (2004) Eye shape in emmetropia and myopia. Invest Ophthalmol Vis Sci 45:3380-3386

7. Atchison DA, Markwell EL, Kasthurirangan S, Pope JM, Smith G, Swann PG (2008) Age related changes in optical and biometric characteristics of emmetropic eyes. J Vision 8(4):29, $1-20$

Presentation at a conference- none

This work has not been submitted elsewhere

Clinical Trial Registration number-not relevant

D. A. Atchison $(\triangle)$

School of Optometry and Vision Science and Institute of Health and

Biomedical Innovation, Queensland University of Technology, 60

Musk Avenue, Kelvin Grove, QLD 4059, Australia

e-mail: d.atchison@qut.edu.au 